\title{
A Prospective analysis of the efficacy of JESS (Joshi's External Stabilizing System) fixator in management of complex tibial plateau fractures.
}

\author{
Sunil Kumar ${ }^{1}$, Dinesh Kumar ${ }^{2}$, Surendra Kumar ${ }^{3}$, Anil Srivastava ${ }^{4}$, \\ Vinit Jaiswal ${ }^{5}$ \\ 1. (MBBS, M.S. Orth,) Associate Professor, Dept. Of Orthopaedic Surgery. U.P. Rural Institute Of Medical \\ Sciences \& Research, Saifai, Etawah, (U.P.). India. \\ 2. (MBBS, M.S. Orth,) Assistant Professor, Dept. Of Orthopaedic Surgery. U.P. Rural Institute Of Medical \\ Sciences \& Research, Saifai, Etawah, (U.P.). India. \\ 3. (MBBS, M.S. Orth, Lecturer, Dept. Of Orthopaedic Surgery. U.P. Rural Institute Of Medical Sciences \& \\ Research, Saifai, Etawah, (U.P.). India. \\ ${ }^{4,5}$ (MBBS, M.S. Orth,) Senior Resident, Dept. Of Orthopaedic Surgery. U.P. Rural Institute Of Medical \\ Sciences \& Research, Saifai, Etawah, (U.P.). India.
}

\begin{abstract}
:
Objective: Complex tibial plateau fractures are caused by variety of mechanisms and have different fracture patterns, may be associated with soft tissue injuries, compartment syndrome, blistrations. Restoration of joint congruity, limb alignment, early range of motion, with a stable knee is difficult at times. We studied efficacy of JESS (Joshi's External Stabilizing System) with or without limited fixations in these complex tibial plateau fractures.

Material and Methods: 32 patients of complex tibial plateau fractures (Schatzker type V and VI) associated with severe soft tissue injury, crushing, compartment syndrome were studied. All cases were treated by Joshi's External Stabilizing System with or without limited fixation by cannulated cancellous screws. Progress and complaints of the patients were recorded in accordance with Rick/Delamertier and Meason Hohl scoring system. Follow up of patients was at regular interval of 4 weeks for 6 months and thereafter 6 monthly.

Results: Out of 32 patients of complex tibial plateau fractures ( 23 Schatzker Type VI and 9 Type V) with mean age 37.47 (range 20-68) years had right knee injury $(n=20)$ more than left knee $(n=12)$. Mean interval period between injury and the surgery was 6.44 (range 3-16) days. Mean duration of hospital stay was 9.03 (range 525) days. Mean range of flexion was $112.19^{0}$ (range $75^{0}-130^{\circ}$ ), Extensor lag of $5^{0}-10^{0}$ seen in 4 cases. 26 patients have no limitation in activity. Post operative complications like superficial / Pin tract infection in 7 , deep infection in 1 and non-union in 1 case were observed. Excellent in 26, good in 4 and satisfactory results in 2 patients were observed in this study.

Conclusion: JESS (Joshi's External Stabilizing System) combined with limited fixation is a good alternative technique in management of complex tibial plateau fractures. This technique works on the principle of ligamentotaxis. JESS construct helps to take care of wound and dressings and permits early physiotherapy and range motion exercises.
\end{abstract}

Key words: Complex tibial plateau fractures; ligamentotaxis; jess fixator.

\section{Introduction}

Knee is complex weight bearing joint, even small irregularities in articular surface or minimal instability lead to stiffness of knee with below normal range of motion. Treatment of complex condylar fractures of tibia is great challenge to orthopaedic surgeons as they are usually a result of high velocity trauma and associated with considerable soft tissue injuries requiring coverage, compartment syndrome, vascular injuries, ligaments and meniscal tears and eventually knee arthrosis [1], [2].These complex injuries are result of axial loading combined with valgus/varus forces [3]. These injuries severely affect selection of surgical procedure, treatment and poor outcomes occur in terms of infections, wound problems, articular collapse, joint stiffness and mal-alignment of the knee [4]. Casting and traction in these situations produce poor results. Aim of treatment is to restore joint anatomy, preserve knee functions and prevent late degenerative arthritis. Operative procedures are recommended to restore joint congruity, limb alignment and to allow early, stable knee motion. Open reduction and internal fixation of these complex fractures with unilateral or double plating further complicate situation as it devitalizes the tissues, skin and bone fragments.

High infection rates after open reduction and internal fixation on using plates are reported [5], [6]. Newer advancements and designs of internal and external fixation have modified techniques of fracture fixation. 
Orthopaedic surgeon has to apply both his scientific analyzing abilities and technical expertise in treating them. Currently such injuries are being managed by variety of surgical techniques and implants varying from less invasive to extensive open reduction and internal / external, minimal fixation with or without arthroscopic assistance. Periarticular cancellous screw and kirschner wire fixation in complex intra-articular fractures help to restore anatomy and attain stable fixation allowing easy wound care, early joint mobilization with minimal soft tissue disruption [7]. We studied efficacy of JESS fixator with or without limited screw fixations based on principle of ligamentotaxis for management of such complex tibial plateau fractures.

\section{Material And Methods}

The study conducted at UP RIMS\&R, Saifai, Etawah between April 2010 - June 2013 and total 32 patients of complex tibial plateau fractures selected and treated by JESS or JESS with limited screw fixation. The study included only Schatzker type V (bicondylar fracture pattern), Schatzker type VI (bi-condylar fracture with metaphyseo-diaphyseal dissociation) which were not associated with neuro vascular deficit, dislocation of knee, ipsi-lateral lower limb injury, any previous fracture / pathology or surgery, any previous history of neuromuscular weakness (polio etc.).

These injuries were either compound (open) wounds or closed fractures with compartment syndrome or severe swelling, crushing, poor skin condition where other methods of fixations like plate / CC screw fixation or and plaster cast / open reduction and internal fixation at that point could not be not preferred [figure1].

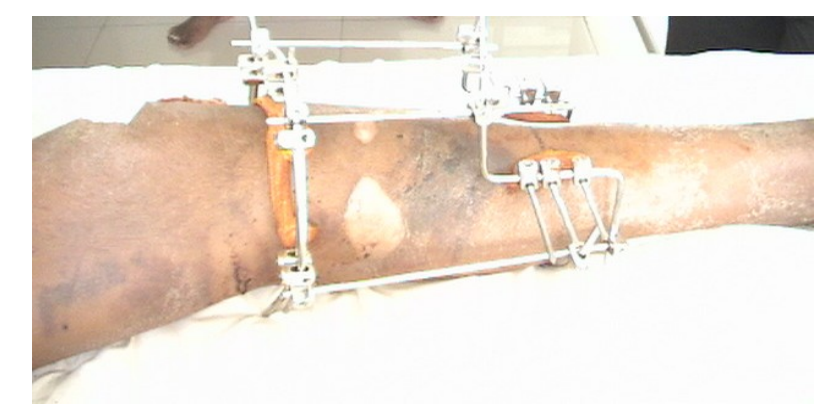

Figure-1

Figure-1:Clinical photograph of patient with complex tibial plateau fracture showing blisterations, poor soft tissue and skin condition, managed with JESS, deferring routine plate osteosynthesis.

In these 32 patients JESS fixation with / without limited internal fixation with CC screw was done as associated soft tissue injuries did not affect the timing of percutaneous fixation.Pre operative immobilization by calcaneal skeletal traction and appropriate antibiotics given regularly for prophylaxis from infections. AnteroPosterior / Lateral view of X-rays, [figure2]

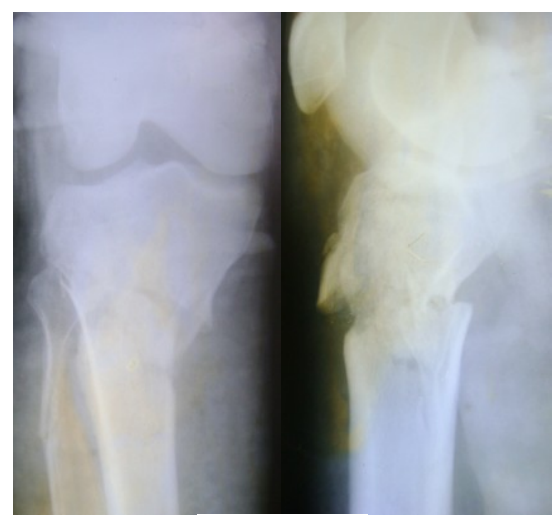

Figure 2

Figure -2: Anteroposterior and lateral view of radiograph showing complex tibial plateau fracture (Schatzker type VI). 
CT and MRI scan were done to assess the extent of associated injuries like ligament and meniscal tears, pattern of tibial plateau fractures, depression and articular comminution. We followed Schatzker staging system for classification for fracture in our study.

\section{Implants:}

$\begin{array}{ll} & \text { Kirschner wires }(2 \mathrm{~mm}, 2.5 \mathrm{~mm}, 3 \mathrm{~mm}) \\ \quad \text { Connecting rods }(3 \mathrm{~mm}, 4 \mathrm{~mm}) \\ \quad \text { Z-rods }(4 \mathrm{~mm}) \\ \quad \text { 6.5 Jess blocks } \\ \end{array}$

\section{Technique}

Reduction of comminuted fragments was achieved on traction table using principle of ligamentotaxis under image guidance. An articular incongruity $>3 \mathrm{~mm}$ indicated open reduction with limited incision. After achieving acceptable reduction and restoration of anatomy with k-wires of $2-3 \mathrm{~mm}, 6.5 \mathrm{~mm}$ cannulated cancellous screw were placed in juxtra articular bone to maintain reduction. Screw fixation worked as lag screw in centre of mid portion of condylar fragments perpendicular to fracture line to produce maximum compression. $3 \mathrm{~K}$-wires $(2.5 \mathrm{~mm})$ were inserted in juxtra articular bone parallel to articular surface at different angles. $3 \mathrm{~K}$ wires $(3 \mathrm{~mm})$ were placed parallel to each other in distal tibia fragment. Additional K-wires each in proximal and distal fragments were used to maintain mechanical axis and prevent rotation of fragments [figure-3]. Metaphyseo-diaphyseal comminution is spared, ligamentotaxis helps in restoration of anatomy and alignment [figure-4].

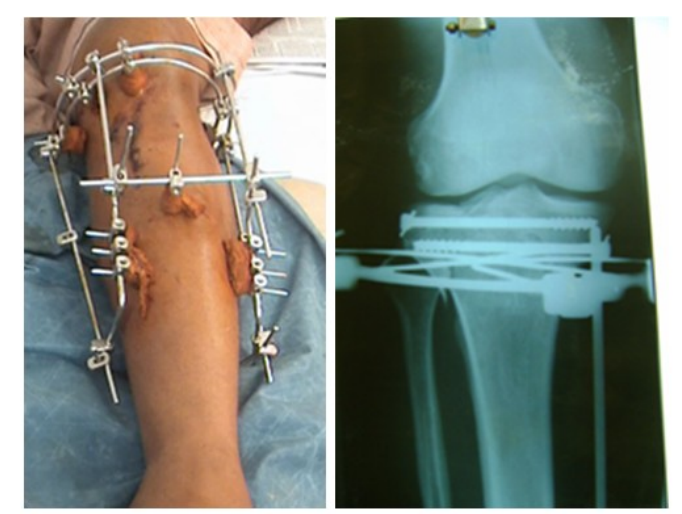

Figure 3: Clinical and radiological photograph showing restoration of mechanical axis, anatomical reduction, compression of condylar fragments with cannulated cancellous screws and stabilization with JESS.

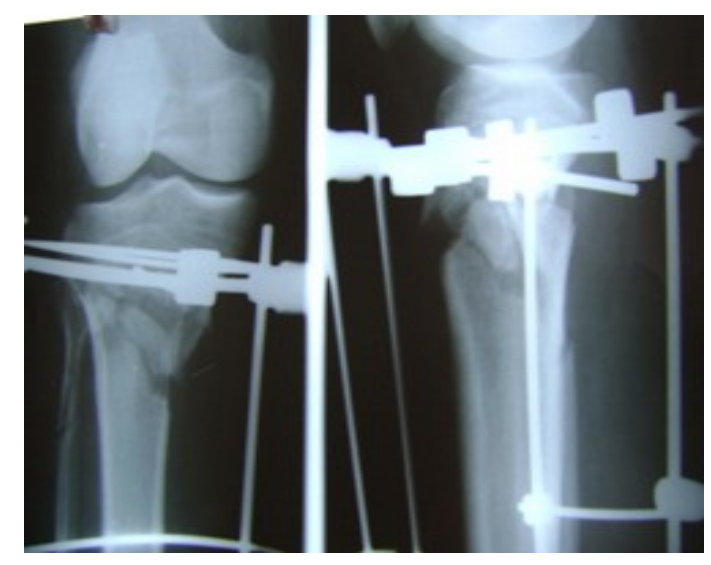

Figure 4: Postoperative antero-posterior and lateral radiograph showing alignment restoration, fracture fixation by fine kirschner wires with spanning area of metaphyseo-diaphyseal comminution through ligamentotaxis. 
All these K-wires in proximal and distal fragments are, contacted to each other by JESS blocks and rods to make stable JESS construct.

Regular wound check and pin tract care, dressing done and appropriate antibiotics administered for prophylaxis of infection. Early range of motion exercises promoted as patients tolerance to pain [figure-5] . Partial weight bearing at 12 to 14 weeks and full weight bearing allowed after clinical or radiological union [figure-6] .

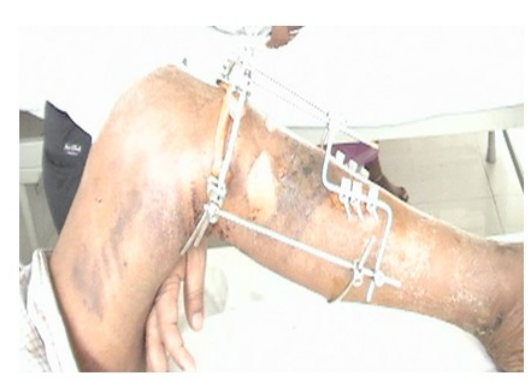

Fig.:5(a)

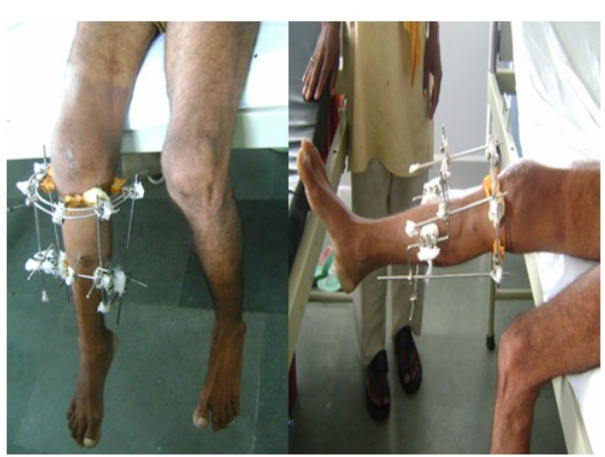

fig.:5(b)

Figure 5(a\&b): Clinical photograph showing physiotherapy in early postoperative period.

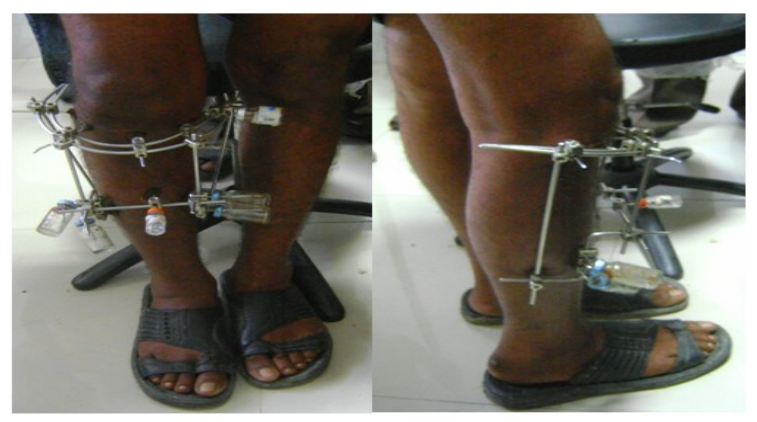

Figure 6

Figure 6: Clinical photograph showing early weight bearing with JESS frame.

JESS construct removed after clinical or radiological union [figure-7]. PTB brace / support, sticks were given depending upon the requirement of the patients. Patients were followed up at regular interval of 4 weeks for initial 06 months and thereafter 06 monthly after removal of JESS [figure-8]. Progress and patient complains recorded in accordance with Rick/Delamertier and Mason Hohl scoring system.

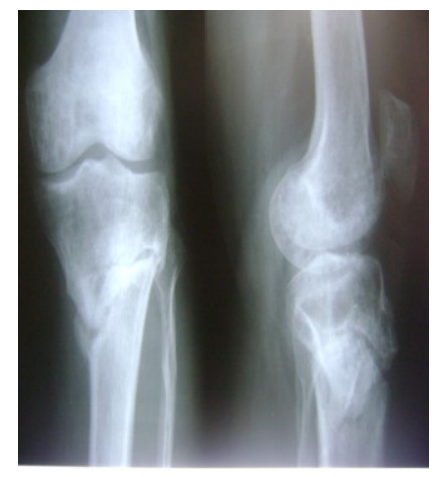

Fig. 7(a)

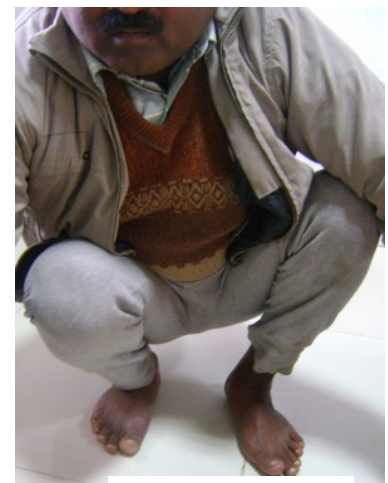

Fig. 7(b)

Figure 7: Antero-posterior and lateral radiograph showing bony union (a), range of flexion (b) after removal of JESS at 20 weeks. 


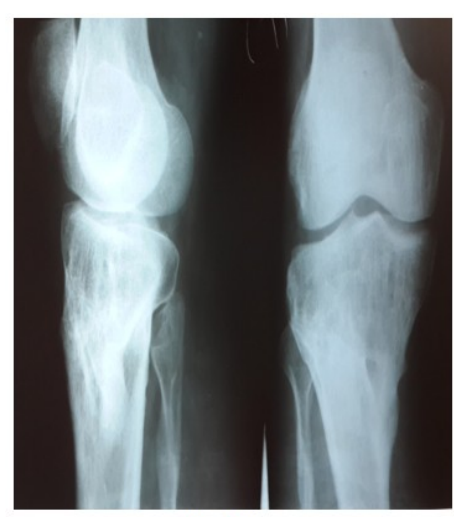

Fig.8(a)

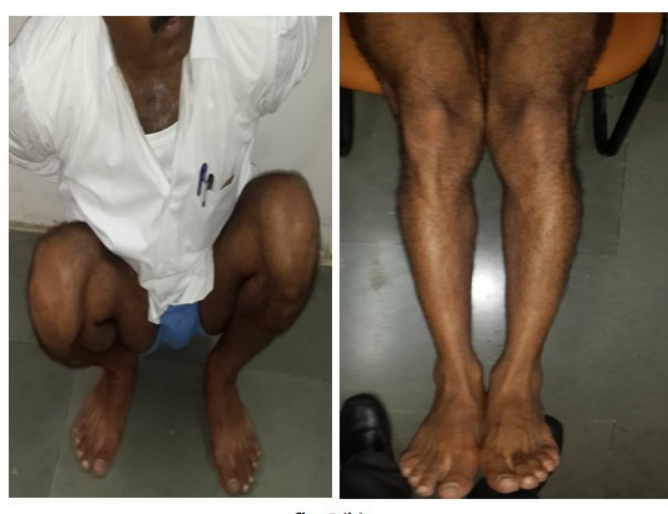

fig.8(b)

Figure 8: Photograph showing radiological bony consolidation (a), functional range of motion (b) at 36 months follow up.

\section{Observations And Result}

Out of total 32 patients of complex tibia plateau fracture (Schatzker type V \& VI) included were 9 open wounds ( 6 compound grade II, 3 compound grade III) and 23 closed injury tibial plateau fracture with poor skin condition, severe swelling, blisterations and compartment syndrome in 3 patients, managed with JESS construct alone or JESS construct with limited fixation with cannulated cancellous screws. Maximum patients $(\mathrm{n}=20)$

were young adults of 20-40 years age group with mean age 37.47 (range 20-68) years (table-1).

Table 1: Demographic distribution of age, day of presentation to hospital and occupation of patients.

\begin{tabular}{|l|l|l|l|l|l|l|l|l|}
\hline \multicolumn{3}{|c|}{ Age } & Day of presentation to hospital & \multicolumn{3}{|c|}{ Occupation } \\
\hline Group & No. & $\%$ & Duration & No. & $\%$ & Category & No. & \% \\
\hline $20-30$ & 11 & 34.37 & $0-1$ & 10 & 31.25 & Labour & 7 & 21.87 \\
\hline $31-40$ & 9 & 28.12 & $2-3$ & 11 & 34.37 & Farmer & 7 & 21.87 \\
\hline $41-50$ & 7 & 21.87 & $4-6$ & 4 & 12.50 & Housewife & 1 & 3.12 \\
\hline $51-60$ & 4 & 12.50 & $7-10$ & 5 & 15.62 & Student & 3.12 & 1 \\
\hline $61-70$ & 1 & 3.12 & 10 & 2 & 6.25 & Business/Service & 16 & 50.00 \\
\hline Total & $\mathbf{3 2}$ & $\mathbf{1 0 0 . 0 0}$ & Total & $\mathbf{3 2}$ & $\mathbf{1 0 0}$ & Total & $\mathbf{3 2}$ & $\mathbf{1 0 0}$ \\
\hline
\end{tabular}

Male $(n=28)$ patients greatly outnumbered female $(n=4)$. Right knee injury $(n=20)$ more common than left knee $(n=12)$. Occupation wise service/business class $(n=16) 50 \%$ sustained high tibial plateau fracture followed by labour and farmer class $(n=7)$ each. This high energy trauma was mainly due to road traffic accidents $(n=28)$ and fall from height $(n=4)$. Type VI Schatzker fracture pattern $(n=23)$ was more observed than Schatzker type V $(n=9)$ [ table-2].

Table-2: Demographic distribution of sex, pattern of injury and mode of injury in patients.

\begin{tabular}{|c|c|c|c|c|c|c|c|c|c|c|c|c|c|c|}
\hline \multicolumn{3}{|c|}{ Sex } & \multicolumn{9}{|c|}{ Pattern of Injury } & \multicolumn{3}{|c|}{ Mode of injury } \\
\hline Group & No. & $\%$ & Type & No. & $\%$ & Side & No. & $\%$ & Tyре & No. & $\%$ & Group & No. & $\%$ \\
\hline Male & 28 & 87.50 & $\begin{array}{l}\text { Simple } \\
\text { (closed) }\end{array}$ & 23 & 71.87 & Right & 20 & 62.50 & $\begin{array}{l}\text { Schatzker } \\
\mathrm{V}\end{array}$ & 9 & 28.12 & RTA & 28 & 87.50 \\
\hline Female & 4 & 12.50 & $\begin{array}{l}\text { Compound } \\
\text { (open) }\end{array}$ & 9 & 28.12 & Left & 12 & 37.50 & $\begin{array}{l}\text { Schatzker } \\
\text { VI }\end{array}$ & 23 & 71.87 & $\begin{array}{ll}\text { Fall from } \\
\text { height }\end{array}$ & 4 & 12.50 \\
\hline Total & 32 & 100 & Total & 32 & 100 & Total & 32 & 100 & Total & 32 & 100 & Total & 32 & 100 \\
\hline
\end{tabular}

On statistical analysis of data [table-3], we observed after injury mean time of patient presentation to hospital was 3.50 (range 1- 12) days. Mean interval period between injury and surgery was 6.44 (range 3-16) days. Mean duration of hospital stay was 9.03 (range 5-25) days. The mean interval between surgery and weight bearing was 13.78 (range 12-17) weeks. 
Table-3: Statistical analysis of significant variables

\begin{tabular}{|l|l|l|l|l|l|}
\hline Variables & Mean & Range & Mean \pm SD & SEM & CI (95\%) \\
\hline Age (years) & 37.47 & $20-68$ & $37.47 \pm 12.29$ & 2.17 & $33.04-41.90$ \\
\hline Day of presentation to hospital (days) & 3.50 & $1-12$ & $3.50 \pm 3.03$ & 0.54 & $2.03-4.97$ \\
\hline $\begin{array}{l}\text { Duration between injury and surgery } \\
\text { (days) }\end{array}$ & 6.44 & $3-16$ & $6.44 \pm 3.41$ & 0.60 & $5.21-7.67$ \\
\hline Duration of hospital stay (days) & 9.03 & $5-25$ & $9.03 \pm 4.10$ & 0.72 & $7.55-10.51$ \\
\hline Range of flexion (degrees) & 112.19 & $75-130$ & $112.19 \pm 14.31$ & 2.53 & $107.03-117.35$ \\
\hline Time of weight bearing (weeks) & 13.78 & $12-17$ & $13.78 \pm 1.48$ & 0.26 & $13.25-14.31$ \\
\hline
\end{tabular}

Abbreviations: SD-Standard Deviation, SEM-Standard Error of Mean, CI-Confidence Interval.

Surgical interventions were delayed mainly due to poor soft tissue condition, impending compartment syndrome and due to delay in presentation to hospital. Fasciotomy in 4 patients and blood transfusion in 6 patients was required. Transfusion of blood was mainly required in open wound cases. Mean follow up of patient was 16 (range 6 - 36) months. Soft tissue coverage was required in 2 cases.

The functional outcomes were recorded in accordance with Rick/Delamertier and Mason Hohl scoring system (table-4).

Table - 4: Functional outcomes in accordance to Rick/Delamertier and Mason Hohl scoring system.

\begin{tabular}{|c|c|c|c|c|}
\hline Functional Outcomes & Range & Score & $n=$ number of patients & Percentage $(\%)$ \\
\hline Pain & $\begin{array}{l}\text { Nil } \\
\text { Occasionally } \\
\text { Over pin tract } \\
\text { During walking }\end{array}$ & $\mid \begin{array}{l}30 \\
25 \\
20 \\
15\end{array}$ & $\begin{array}{l}18 \\
9 \\
4 \\
1 \\
\end{array}$ & $\begin{array}{l}56.2 \\
28.1 \\
12.5 \\
3.1 \\
\end{array}$ \\
\hline Function (Movements) & $\begin{array}{l}\text { Movement } \geq 120^{\circ} \\
120^{\circ}-90^{\circ} \\
90^{\circ}-60^{\circ} \\
<60^{\circ}\end{array}$ & $\mid \begin{array}{l}30 \\
25 \\
20 \\
15\end{array}$ & $\begin{array}{l}15 \\
15 \\
2 \\
0\end{array}$ & $\begin{array}{l}46.9 \\
46.9 \\
6.2 \\
0.0\end{array}$ \\
\hline Activity & $\begin{array}{l}\text { No Limitation } \\
\text { Limited to walking } \\
\text { Assistance required }\end{array}$ & $\begin{array}{l}15 \\
10 \\
05\end{array}$ & $\begin{array}{l}26 \\
5 \\
1\end{array}$ & $\begin{array}{l}81.2 \\
15.6 \\
3.1 \\
\end{array}$ \\
\hline Infection & $\begin{array}{l}\text { Nil } \\
\text { Superficial } \\
\text { Deep }\end{array}$ & $\begin{array}{l}05 \\
03 \\
01\end{array}$ & $\begin{array}{l}24 \\
7 \\
1\end{array}$ & $\begin{array}{l}75.0 \\
21.9 \\
3.1 \\
\end{array}$ \\
\hline Loss of extension & $\begin{array}{l}\text { Nil } \\
<10^{0} \\
>10^{0} \\
\end{array}$ & $\begin{array}{l}05 \\
03 \\
01\end{array}$ & $\begin{array}{l}28 \\
4 \\
0\end{array}$ & $\begin{array}{l}87.5 \\
12.5 \\
0.0 \\
\end{array}$ \\
\hline Instability & $\begin{array}{l}\text { Nil } \\
\text { ACL or MCL or both } \\
2 \& \text { PCL }\end{array}$ & $\begin{array}{l}05 \\
03 \\
01\end{array}$ & $\begin{array}{l}26 \\
6 \\
0\end{array}$ & $\begin{array}{l}81.2 \\
18.8 \\
0.0 \\
\end{array}$ \\
\hline \multicolumn{5}{|l|}{ Radiological Outcomes } \\
\hline $\begin{array}{l}\text { Collapse of articular surface } \\
\text { (Change in varus angle) }\end{array}$ & $\begin{array}{l}<5^{0} \\
5-10^{0} \\
>10^{0}\end{array}$ & $\begin{array}{l}15 \\
10 \\
05\end{array}$ & $\begin{array}{l}25 \\
7 \\
0\end{array}$ & $\begin{array}{l}78.1 \\
21.9 \\
0.0\end{array}$ \\
\hline Varus angle (Residual) & $\begin{array}{l}<10^{0} \\
10-15^{0} \\
15-20^{0} \\
>20^{0}\end{array}$ & $\begin{array}{l}20 \\
15 \\
10 \\
05\end{array}$ & $\begin{array}{l}26 \\
6 \\
0 \\
0\end{array}$ & $\begin{array}{l}81.2 \\
18.8 \\
0.0 \\
0.0\end{array}$ \\
\hline \multicolumn{5}{|l|}{ GRADING } \\
\hline Total Score & $\begin{array}{l}\text { Excellent (E) } \\
\text { Good }(G) \\
\text { Satisfactory (S) } \\
\text { Fair (F) } \\
\text { Poor (P) }\end{array}$ & $\mid \begin{array}{l}100-125 \\
90-100 \\
80-90 \\
70-80 \\
<70\end{array}$ & $\begin{array}{l}26 \\
4 \\
2 \\
0 \\
0\end{array}$ & $\begin{array}{l}81.2 \\
12.5 \\
6.2 \\
0.0 \\
0.0\end{array}$ \\
\hline
\end{tabular}

No or occasional pain was observed in 27 patients, 5 had pain over pin tract. Mean range of flexion $112.19^{\circ}$ (range $75^{\circ}-130^{\circ}$ ) and extension lag of $5^{0}-10^{0}$ was observed in 4 cases. No limitation of activity in 26 cases, limited to walking in 5, assistance in activity was required in 1 case. Collapse of articular surface (change in varus angle) $<5^{0}$ in 25 cases and $5^{0}-10^{0}$ in 7 cases were seen. 24 patients had no infection and superficial/pin tract infection in 7 cases, deep infection in 1 and non-union in 1 was observed. The non-union was observed in diaphyseal region requiring bone grafting and fixation. Post operative complications like myositis ossificans, peroneal nerve palsy, pulmonary embolism, deep vein thrombosis were not observed. Excellent results in 26, good in 4 and satisfactory results in 2 patients were observed. 


\section{Discussion}

Proximal tibia fractures are caused by variety of mechanisms. Treatment of complex tibial plateau fractures and irregularities in articular surfaces or minimal instability following a injury is difficult in terms of restoring function, union and correcting anatomy. These fractures are usually a result of high velocity trauma and are frequently associated with significant articular depression displacements, metaphysio-diaphyseal dissociation [3]. Open wounds or extensive closed soft tissue injury to proximal tibia adds to challenges in adopting surgical procedure. Bracing, casting or tractions have not given optimal results [8]. Unicondylar tibia / lateral condyle fixation or limited C.C. Screw fixations have not been able to provide rigid fixation and resulted in collapse of unsupported tibial plateau condyle producing deformity and instability with loss of functional range of motion later [9]. Spanning fixators restrict the early movements and articular healing [10]. Open reduction and Internal fixation with dual plating techniques have high deep infection rate $(80 \%)$ in complex bicondylar plateau fracture as large amount of soft tissue stripping is required for plate fixation to achieve rigid fixation [5],[11],[12],[13]. 23\% infection rate with dual plating of bicondylar fractures [5],[12]. 87.5\% deep infection and $100 \%$ complication rate for comminuted or bicondylar plateau fracture [13]. $12 \%$ infection rate in ring fixator [6].

High infection rate have been reduced with minimal invasive, indirect reduction and limited surgical techniques for restoration of joint congruity by hybrid or fine wire fixation and spanning of meta- diaphyseal fracture [14],[15],[16],[17],[18]. Management of complex tibial plateau fractures with limited internal fixation and external fixator is satisfactory technique [16]. Concept of spanning area of fracture comminution to achieve indirect fracture reduction and limited internal fixation have decreased infection rates and increased fracture healing. Less invasive technique and procedure provide stable fixation to fracture fragments, restored anatomy and permit early mobilization and help to prevent further soft tissue injury and easy wound care is possible [19]. JESS fixation works on the principle of ligamentotaxis to help achieve and restore articular congruity in both sagittal and coronel planes, metaphysio-diaphyseal alignment, when used with or without cancellous screw [20],[21],[22],[23].

Ligamentotaxis helps in closed anatomical reduction of fracture fragments and limited open reduction and fixation with cancellous screws minimizes further soft tissue damage. Screws placed in lag fashion helps to compress the fractured condyles, support subchondral bone and prevent further articular collapse. JESS combined with cancellous screws has optimal metaphyseal purchase, helps to allow early physiotherapy and weight bearing.

JESS is minimally invasive technique with shorter operating time, requiring no or limited incision. Blood loss is less, hospital stay is shorter. JESS also has lower rates of infection/complications with added advantages of better and easy wound care, good patient compliance at lower cost.

\section{Conclusion}

JESS (Joshi's External Stabilizing System) construct as an external fixator fulfills the requirement of optimal surgical treatment of these complex high energy tibial plateau fractures combined with limited periarticular internal fixation with cancellous screws.

\section{References}

[1] Bennett WF, Browner B: Tibial plateau fractures: A study of associated soft tissue injuries. J Orthop Trauma 8:183-188,1994

[2] Honkonen SE : Degenerative arthritis after tibial plateau fractures. J Orthop Trauma 9:273-277,1995

[3] Watson JT. High-energy fractures of the tibial plateau. Orthop Clin North Am 1994;25:723-52.

[4] Cole PA, Zlowodzki M, Kregor PJ. Treatment of proximal tibia fractures using the less invasive stabilization system: surgical experience and early clinical results in 77 fractures. J Orthop Trauma 2004;18:528-35.

[5] Mallik AR, Covall DJ, Whitelaw GP: Internal versus external fixation of bicondylar tibial plateau fractures. Orthop Rev 21:143314336,1992

[6] Veri JP, Blachut P, O’Brien P, et al: High-grade tibial plateau fractures: A matched cohort study comparing internal fixation and ring fixator methods. OTA Abstract, Charlotte, NC, 1999, p 184.

[7] Piper KJ, Won HY, Ellis AM. Hybrid external fixation in complex tibial plateau and plafond fractures: an Australian audit of outcomes. Injury 2005;36:178-84.

[8] DeCoster TA, Nepola JV, el-Khoury GY. Cast brace treatment of proximal tibia fractures. A ten-year follow-up study. Clin Orthop Relat Res 1988;231:196-204.

[9] Rangitsch MR, Duwelius PJ, Colville MR. Limited internal fixation of tibial plateau fractures: a prospective protocol. J Orthop Trauma1993;7:168-9.

[10] Salter RB, Simmonds DF, Malcolm BW, Rumble EJ, MacMichael D, Clements ND. The biological effect of continuous passive motion on the healing of full-thickness defects in articular cartilage. An experimental investigation in the rabbit. J Bone Joint Surg Am 1980;62:1232-51.

[11] Hutson Jr JJ, Zych GA: Infections in periarticular fractures of the lower extremity treated with tensioned wire hybrid fixators. J Orthop Trauma 12:214-218, 1998.

[12] Moore TM, Patzakis MJ, Harvey JP: Tibial plateau fractures: Definition, demographics, treatment rationale, and long-term results of closed traction management or operative reduction. J Orthop Trauma 1:97-119, 1987.

[13] Young MJ, Barrack RL: Complications of internal fixation of tibial plateau fractures.Orthop Rev 23:149-154,1994 
[14] Dendrinos GK, Kontos S, Katsenis D, et al: Treatment of high-energy tibial plateau fractures by the Ilizarov circular fixator. J Bone Joint Surg Br 78:710-717, 1996.

[15] Hohl M, Luck V: fractures of tibial condyle.J Bone Joint Surg Am 38:1001-1008,1956

[16] Marsh JL, Smith ST, Do TT: External fixation and limited internal fixation for complex fractures of the tibial plateau. J Bone Joint Surg Am 77:661-673, 1995.

[17] Ries MD, Meinhard BP: Medial external fixation with lateral plate internal fixation in metaphyseal tibia fractures: A report of eight cases associated with severe soft-tissue injury. Clin Orthop 256:215-223, 1990.

[18] Stamer DT, Schenk R, Staggers B, et al: Bicondylar tibial plateau fractures treated with a hybrid ring external fixator: A preliminary study. J Orthop Trauma 8:455-461, 1994.

[19] Kataria H, Sharma N, Kanojia RK. Small wire external fixation for high-energy tibial plateau fractures. Journal of Orthopaedic Surgery 2007;15(2):137-43.

[20] Brown TD, Anderson DD, Nepola JV, et al: Contact stress aberrations following imprecise reduction of simple tibial plateau fractures. J Orthop Res 6:851-862,1988

[21] Moore TM, Harvey JP: Roentgenographic measurement of tibial-plateau depression due to fracture. J Bone Joint Surg Am 56:155$160,1974$.

[22] Porter BB: Crush fractures of the lateral tibial table. J Bone Joint Surg Br 52:676-687, 1970.

[23] Zahid M, Sherewani MKA, Siddiqui YS, Abbas M, Asif N, Sabir Ab. The role of the JESS (Joshi's External Stabilization System) fixator in the management of tibial plateau fractures which are associated with severe soft tissue injuries. Journal of clinical and diagnostic research.2010 December;940:3356-3361. 